\title{
Allogeneic Multipotent Adult Progenitor Cells
}

National Cancer Institute

\section{Source}

National Cancer Institute. Allogeneic Multipotent Adult Progenitor Cells. NCI Thesaurus. Code C77874.

\begin{abstract}
A biologic product that consists of undifferentiated stem cells, obtained from adult bone marrow or other non-embryonic tissue sources, that are expanded in vitro and deposited in master cell banks for "off-the-shelf" use, with potential hematopoiesis-inducing and immunomodulating activities. Allogeneic multipotent adult progenitor cells (MAPCs) are non-immunogenic due to the lack of major histocompatibility ( $\mathrm{MHC}$ ) molecule expression, and so elicit no immune response upon administration. In vivo, bone marrowderived adult stem cells are capable of maturing into a broad range of cell types and may help restore the immune system by producing multiple therapeutic molecules in response to inflammation and tissue damage.
\end{abstract}

